\title{
Using vegetation spectral indices to detect oil pollution in the Niger Delta
}

\section{Bashir Adamu, Kevin Tansey \& Booker Ogutu}

To cite this article: Bashir Adamu, Kevin Tansey \& Booker Ogutu (2015) Using vegetation spectral indices to detect oil pollution in the Niger Delta, Remote Sensing Letters, 6:2, 145-154, DOI: $10.1080 / 2150704 X .2015 .1015656$

To link to this article: http://dx.doi.org/10.1080/2150704X.2015.1015656

\section{(c) 2015 The Author(s). Published by Taylor \& Francis.}

\section{曲 Published online: 26 Feb 2015.}

Submit your article to this journal $\pi$

Џلll Article views: 833

Q View related articles ¿

\section{View Crossmark data $₫$}




\title{
Using vegetation spectral indices to detect oil pollution in the Niger Delta
}

\author{
Bashir Adamu*, Kevin Tansey, and Booker Ogutu \\ Department of Geography, Centre for Landscape and Climate Research, University of Leicester, \\ Leicester, UK
}

(Received 4 August 2014; accepted 31 January 2015)

\begin{abstract}
Vegetation health and vigour may be affected by oil leakage or pollution. This effect can alter a plant's behaviour and may be used as evidence for detecting oil pollution in the environment. Satellite remote sensing has been shown to be an effective tool and approach to detect and monitor vegetation health and status in polluted areas. Previous research has used vegetation indices derived from remotely sensed satellite data to monitor vegetation health. This study investigated the potential for using broadband multispectral vegetation indices to detect impacts of oil pollution on vegetation conditions. Twenty indices were explored and evaluated in this study. The indices use data acquired at the visible, near infrared and shortwave infrared wavelengths. Comparative index values from the 37 oil polluted and non-polluted (control) sites show that 12 Broadband multispectral vegetation indices (BMVIs) indicated significant differences $(p$-value $<0.05)$ between pre- and postspill observations. The $12 \mathrm{BMVI}$ values at the polluted sites before and after the spill are significantly different with the ones obtained on the spill event date. The result at the nonpolluted (control) sites shows that 11 of the 20 BMVI values did not indicate significant change and remained statistically invariant before and after the spill date ( $p$-value $>0.05$ ). Therefore, it can be stated that, in this study, oil spills seem to result in biophysical and biochemical alteration of the vegetation, leading to changes in reflectance signature detected by these indices. Five spectral indices (normalized difference vegetation index (NDVI), soil-adjusted vegetation index (SAVI), adjusted resistant vegetation index (ARVI2), green near infrared (G/NIR) and green shortwave infrared $(\mathrm{G} / \mathrm{SWIR})$ ) were found to be consistently sensitive to the effects of oil pollution on vegetation and hence could be used to map and monitor oil pollution in vegetated areas.
\end{abstract}

\section{Introduction}

Hydrocarbons may reach vegetation when dissolved in the groundwater in the root zone and sometimes via air surrounding it. The uptake through roots and direct contact between soil and plant tissues are also media through which organic contaminants enter plants (Liu et al. 2007). The effects may depend on the type and quantity of chemicals involved and the vegetation type. Different vegetation types have varying sensitivity to hydrocarbons (UNEP 2011). Simonich and Hites (1995) showed that settling down of hydrocarbon particulates and their gaseous contents on leaves and intake via leaf stomata may affect the health of vegetation. Other researchers have also reported impacts of oil pollution from hydrocarbon leakages on vegetation health and vigour (for example Van Der Meer et al. 2002, 2008, 2009). Remote

*Corresponding author. Email: ba108@le.ac.uk 
sensing approaches and techniques such as vegetation spectral indices have proven to be effective in detecting and monitoring impacts of hydrocarbon leaks on vegetation health (Van Der Meer et al. 2000, 2002, 2007; Noomen, Van Der Werff, and Van Der Meer 2012). The mineral alteration that occurs in the soil and geobotany (e.g. abnormal behaviour of vegetation) has been used as evidence for detecting hydrocarbon leakages (Noomen, Van Der Werff, and Van Der Meer 2012). The change in leaves, stems and trunks is a very good indication of the response of plants to oil contamination or stress (Guyot, Baret, and Jacquemoud 1992; Noomen, Van Der Werff, and Van Der Meer 2012). For example, in leaves changes in chlorophyll concentration due to pollution produce spectral shifts in the 'red edge' absorption near $0.70 \mu \mathrm{m}$. The leaves gradually loose photosynthetic pigments resulting in colour change from green to pale-green, yellowish-green and yellow, a process referred to as chlorosis (Raghavan 2000; Li, Ustin, and Lay 2005). Pollution also causes stems to become ash-brown, dark-brown or darkened after exposure (Li, Ustin, and Lay 2005). It has also been shown that the presence of hydrocarbons causes a change in the internal structure of the plants (Van Der Meer et al. 2000). Areas affected by gas leaks have also been shown to contain low vegetation density (Oliveira, Crosta, and Goncalves 1997).

Traditional field methods for estimating biophysical and biochemical properties of plants provide very accurate information on response of individual plant species to pollution, but are limited in spatial coverage. Satellite remote sensing allows for monitoring the terrestrial vegetation characteristics on a regional, continental and global scale. Vegetation affected by oil pollution experiences changes in the biophysical and biochemical characteristics, which can be detected in changes in reflectance measured using satellite sensors (Van Der Meer et al. 2002). This is because vegetation spectral reflectance is dependent on the chlorophyll and water absorption in the leaves, which get altered by oil pollution. Therefore, vegetation indices derived from satellite data can be used to determine the health of vegetation in areas affected by hydrocarbon pollution. Several researchers (Peñuelas et al. 1993; Zarco-Tejada et al. 2005; Li, Ustin, and Lay 2005; Khanna et al. 2013) have used vegetation indices as the main method for assessing various biophysical and biochemical properties of plants such as chlorophyll concentration, water content and vegetation structure. Broadband multispectral vegetation indices (BMVIs) are mathematical combinations of reflected energy recorded at various wavelengths (Jensen 2014; Teillet, Staenz, and Williams 1997) and have been used by scientists since 1960 s in terrestrial science applications aimed to monitor and characterize earth's vegetation cover from space (Myneni et al. 2002; Saleska et al. 2007). In two previous works, we investigated the potential of vegetation spectral reflectance for detecting pollution (Adamu, Tansey, and Bradshaw 2013) on three sample sites. In another work, we tested and analysed 5 BMVIs on 11 sample polluted and non-polluted sites and found that only the modified soil-adjusted vegetation index (MSAVI) showed potential and capacity for detecting affected vegetation (Adamu, Tansey, and Ogutu 2014). This study is an extension/expansion of the two previous preliminary studies (Adamu, Tansey, and Bradshaw 2013; Adamu, Tansey, and Ogutu 2014). In this work, we evaluated 20 BMVIs, shown in Table 1, derived from Landsat TM and Enhanced Thematic Mapper (ETM) data to determine their usefulness to characterize vegetation in oil polluted areas. The aim of this study was to test and assess which vegetation indices are capable of detecting vegetation affected by oil pollution and what features make them suitable for this task. This was done by assessing the temporal changes in the vegetation indices (pre- and postoil spills) at control sites (where there was no oil spill recorded) and at polluted sites (where oil spills were recorded). The study was undertaken in a mangrove ecosystem dominated by swamp vegetation in the Niger Delta region in Nigeria. 


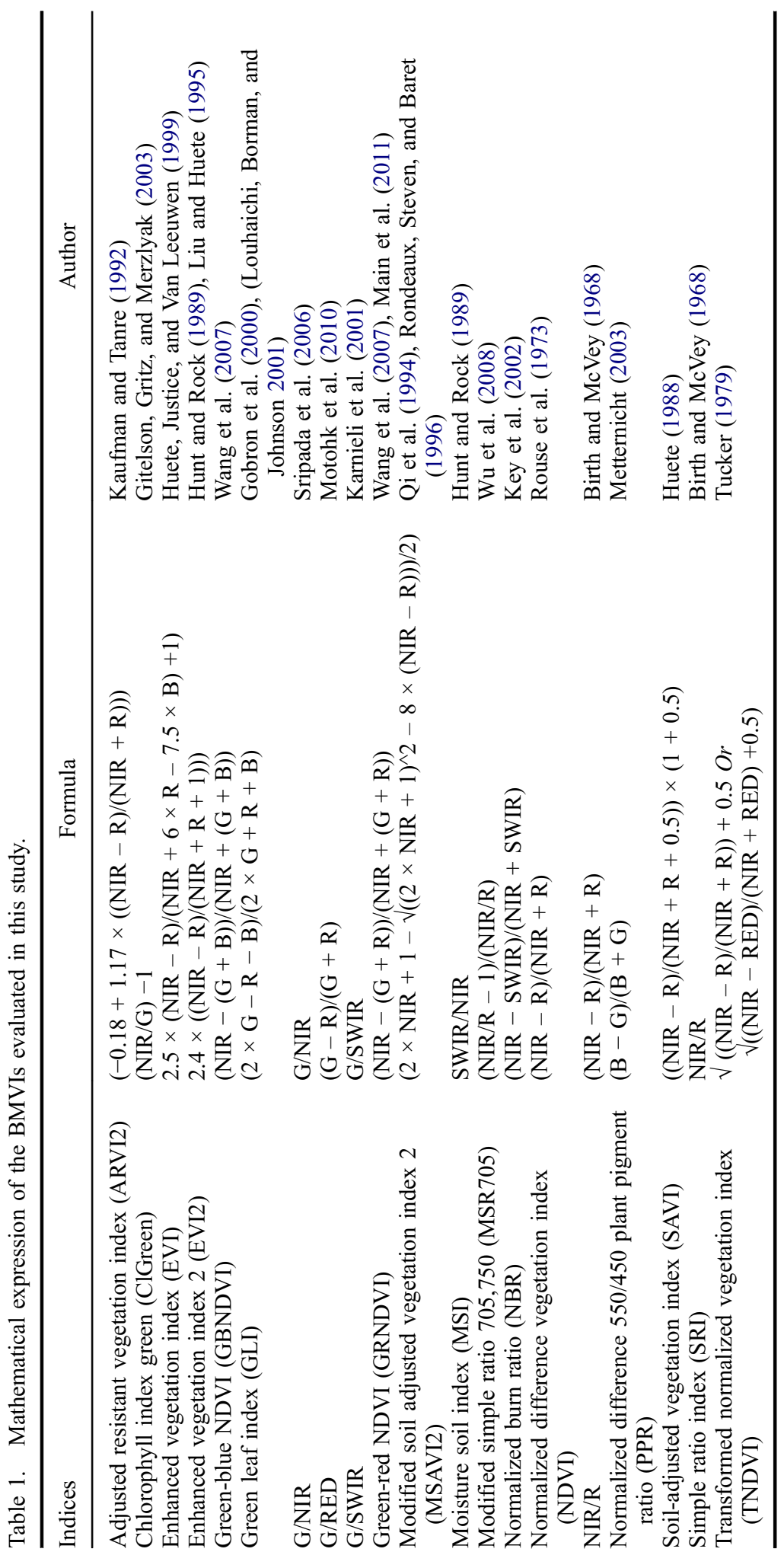




\section{Data and methodology}

Landsat TM and ETM imageries, acquired on 17 January 1986, 19 December 1986, 29 November 1999, 17 December 2000 and 8 January 2003 (path 188, row 57) were analysed in this study. The study area is located on longitude $5.05^{\circ} \mathrm{E}$ and $7.35^{\circ} \mathrm{E}$ and latitude $4.15^{\circ} \mathrm{N}$ and $6.01^{\circ} \mathrm{N}$, it is approximately $1294 \mathrm{~km}^{2}$ fitted into a single frame of Landsat image. The study area is dominantly a mangrove swamp on the coastal wetlands characterized by halophytic trees and shrubs, where fresh and salt water meets. The area is characterized by silt-clay, where oil spills may alter permeability of nutrients and cause toxicity in the soils and lower soil quality which the plants depends on. Oil spills can affect plants through roots, stems, leaves and soils; they can also alter biochemical and geobotanical characteristics of the vegetation at the sites. Settling down of leaked hydrocarbon particulates and their gaseous contents on leaves and intake via leaf stomata may affect the health of vegetation where oil spill occurred (Simonich and Hites 1995).

The ancillary data used include: oil pipeline maps, spill records from 1985 to 2000 and global positioning system (GPS) locations of spill points obtained from the Department of Petroleum Resources, Nigeria (DPRN, Nigeria's oil and gas regulatory agency). There are various factors that influence the choice of sample size for both the ancillary and image data. Some of these factors include cloud cover in image data, availability of data in United States Geological Survey archives, climatic (e.g. seasonality) and environmental conditions of the study area. The images used in this study were restricted to the months of November, December and January because they are relatively free of cloud cover. Topof-atmosphere radiance values were converted to surface reflectance following the method proposed by Chander et al. (2009). In this study, the FLAASH routine available in the Environment for Visualizing Images (ENVI) software was used to change the radiance values into surface reflectance and to undertake atmospheric correction. The difference in weeks between the oil spill event and image acquisition date ranges between 3 and 15 weeks for the study sites. The images before and after each of the oil spill events were processed and used for the temporal analysis.

Thirty seven spill sites that fall along the pipeline routes were considered for analysis within the study area. Stratified sampling was carried out in selecting the sites for analysis and to ensure that the spills are represented by various vegetation covers within the study sites. This will also ensure that we are comparing similar vegetation types from the polluted and non-polluted sites. The sample points were derived from recorded oil spill field data with GPS locations from DPRN archives. An equivalent number of points were also selected in areas which had not experienced any oil spills further away from oil facilities (non-polluted) and used as control sites. Note: both the polluted and non-polluted sites are located in the same swamp vegetated areas as contained in the DPRN oil spill database/records and layers. The areas where oil spills occurred will be referred to as polluted sites $(\mathrm{P})$ and the areas where there were no spills will be referred to as nonpolluted/control sites (NP) for the remainder of this article. Twenty BMVIs (Table 1) were then extracted from these two groups of sites (i.e. polluted and non-polluted sites) within the swamp vegetated areas to ensure that the sample sites have the same vegetation properties. Temporal values of the various BMVIs were computed from the two groups of sites (P and NP sites) for pre- and post-oil spill dates. The period between the spill event and image date is considered as the oil spill date for the purpose of this study. $t$-Test statistics for the BMVI values were also calculated to determine the differences between the periods before and after the oil spill. This analysis provided us with a view on possible 
hydrocarbon effects on biophysical and biochemical characteristics of vegetation before and after the spill at the P sites.

\section{Results}

Twenty BMVIs were assessed to determine their capabilities to detect oil pollution in this study. The potential and capability of these indices were identified using the calculated statistics. From a total of 20 BMVIs investigated, 12 showed significant difference in vegetation conditions before and after $(p$-value $<0.05)$ (Table 2$)$ oil spill. The temporal analysis of the spill sites shows (normalized difference vegetation index (NDVI), SAVI, EVI2, green near infrared (G/NIR), green shortwave infrared (G/SWIR), NIR/R, adjusted resistant vegetation index (ARVI2), EVI, MSR705, TNDVI, green leaf index (GLI) and PPR) significant difference pre- and post-spill observation. At the control sites (nonpolluted) 11 of the 20 indices (NDVI, SAVI, EVI2, GBNDVI, normalized burn ratio (NBR), G/NIR, G/SWIR, MSAVI2, G/R, ARVI2 and SRI) did not indicate significant changes in the index values at pre- and post-spill observation. Table 2 shows the BMVI statistical results obtained before and after the pollution event.

\section{Discussion}

The study evaluated the potential of the BMVIs to detect vegetation affected by oil pollution. These BMVIs were used for temporal analysis (before and after spill), 12 out of the 20 indices indicated significant differences before and after pollution compared to spill event data (Table 2). The common features in these indices are that they include the red (R) and near infrared (NIR) bands in their calculation. The sensitivity shown by these indices to changes in vegetation conditions in polluted areas, before and after the spill, is likely to be due to the $\mathrm{R}$ band being sensitive to chlorophyll in the visible spectrum and NIR being optimal for characterizing vegetation varieties and conditions. Thus, both the R and NIR bands may be capable of indicating changes in chlorophyll content related to changes in vegetation health due to oil pollution. The temporal analysis at the sample $\mathrm{P}$ sites indicated unaffected vegetation before and possible vegetation recovery after the pollution. The result in Table 2 shows that 12 BMVIs indicated significant differences between pre- and post-spill events due to their sensitivity in the polluted environment. We found that the 12 BMVI values at the polluted sites before and after the spill are relatively higher compared to values obtained during the spill event date. While at the non-polluted control sites, Table 2 shows that 11 BMVI values remain relatively the same before and after the spill date. Five BMVIs (NDVI, SAVI, ARVI2, G/NIR and G/SWIR) indicated significant difference before and after the spill at the polluted sites, whilst showing no significant difference over a similar time period in the control site.

A small number of indices which also use the $\mathrm{R}$ and the NIR wavelengths did not show any significant difference in this study area with $p$-value $>0.05$. The reason for this could be due to the fact that these indices correct explicitly for influence of soil background (Liu and Huete 1995). This may be assumed to be the reason why it is less efficient in detecting vegetation affected by pollution in such a swampy environment. An interesting observation from this study is that the vegetation index, which included wavelength that is rarely used such as the $G$ band also seemed to perform well in detecting the temporal vegetation conditions at both the P and NP (control) sites. For example, the BMVIs with green bands (e.g. G/NIR, GRNDVI and G/SWIR) showed 


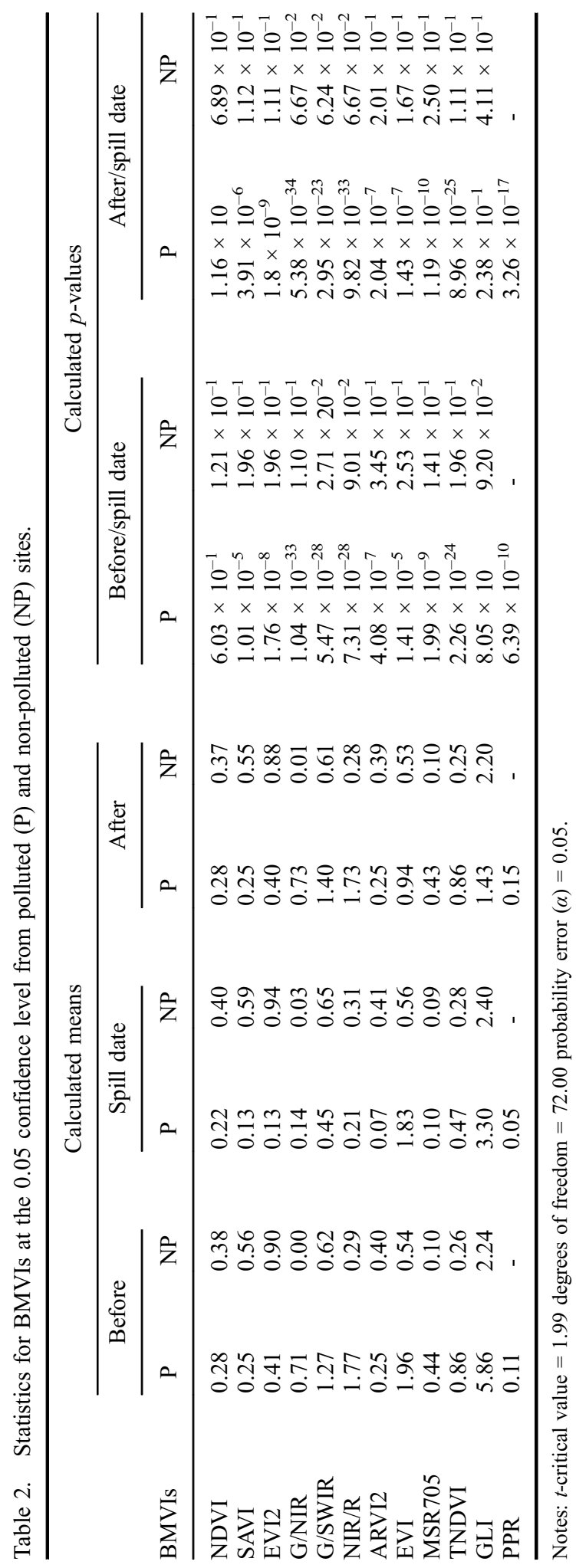


that vegetation conditions before and after spill events at the polluted sites are significantly different and relatively the same at the non-polluted control sites. These findings support assertions made by other studies such as studies of Yoder and Waring (1994) which showed that the green band is well correlated with vegetation parameters, leaf area index for example, and could be used as a substitute to bands such as the red band. Gitelson, Kaufman, and Merzlyak (1996) also showed that the G band was more sensitive to chlorophyll than to the $\mathrm{R}$ channel. The results obtained from vegetation indices calculated using all the mixed three visible bands (i.e. R, G and B bands) which includes the GLI and PPR indicated significant difference in vegetation conditions before and after pollution at the polluted sites. But they (indices) performed poorly by indicating significant difference in temporal changes in vegetation conditions at the nonpolluted control sites. The results of indices that combined the SWIR with the NIR band performed well. For example, the NBR which is designed to discriminate burnt areas (García and Caselles 1991) capable of showing vegetation conditions before and after the spill is relatively the same at the non-polluted sites. However, the indices which combined the SWIR band with the visible (G) band (e.g. the G/SWIR band) performed well in detecting the difference before and after pollution at the polluted sites. Though the index did not indicate any temporal changes in vegetation conditions at the nonpolluted sites (i.e. vegetation conditions before and after pollution at these sites remain relatively the same).

\section{Conclusion}

The evaluation carried out on the 20 BMVIs showed that the best performing indices in detecting vegetation affected by oil pollution were those derived using a combination of reflectance at the visible and NIR wavelengths. It is known that the reflectance signatures of vegetation in these bands are sensitive to any changes in vegetation conditions. Therefore, any changes in vegetation biophysical and biochemical characteristics induced by oil pollution would affect the reflectance signature of vegetation in these bands, which can be detected by indices derived using these bands, as shown in this study. The temporal analysis revealed the differences in vegetation index values before and after pollution (with higher values) compared with the spill event dates (with lower values). Twelve BMVI values showed significant temporal changes at the polluted sites, which were not detected in the non-polluted sites. The temporal changes of the BMVIs at the spill sites could be attributed to biophysical and biochemical alteration in the vegetation due to the effects of oil pollution. Five BMVIs (NDVI, SAVI, ARVI2, G/NIR and G/SWIR) were found to be consistently sensitive to oil pollution effects as shown by their significant temporal changes between pre- and post-spill events. Therefore, these indices could be used for monitoring oil pollution in vegetated areas. Future work will focus on the development of a hybrid vegetation index that combines the elements of the best vegetation indices evaluated in this study to optimize the method for detecting vegetation affected by oil pollution.

\section{Disclosure statement}

No potential conflict of interest was reported by the authors. 


\section{Funding}

This work was supported and funded by the Petroleum Technology Development Fund (PTDF) under the Federal Government of Nigeria [PTDF/E/OSS/PHD/AB/347/11].

\section{References}

Adamu, B., K. Tansey, and M. J. Bradshaw. 2013. Investigating Vegetation Spectral Reflectance for Detecting Hydrocarbon Pipeline Leaks from Multispectral Data. Translated by L. Bruzzone. Dresden: SPIE.

Adamu, B., K. Tansey, and B. Ogutu. 2014. Detection of Oil Pollution along the Pipeline Routes in Tropical Ecosystem from Multi-Spectral Data. Translated by J. J. Braun, 9. Baltimore, MD: SPIE.

Birth, G. S., and G. R. McVey. 1968. "Measuring the Color of Growing Turf with a Reflectance Spectrophotometer1." Agronomy Journal 60 (6): 640-643. doi:10.2134/ agronj1968.00021962006000060016x.

Chander, G., B. L. Markham, and D. L. Helder. 2009. "Summary of Current Radiometric Calibration Coefficients for Landsat MSS, TM, ETM+, and EO-1 ALI Sensors." Remote Sensing of Environment 113 (5): 893-903. doi:10.1016/j.rse.2009.01.007.

García, M. J. L., and V. Caselles. 1991. "Mapping Burns and Natural Reforestation Using Thematic Mapper Data." Geocarto International 6 (1): 31-37. doi:10.1080/10106049109354290.

Gitelson, A. A., Y. Gritz, and M. N. Merzlyak. 2003. "Relationships between Leaf Chlorophyll Content and Spectral Reflectance and Algorithms for Non-Destructive Chlorophyll Assessment in Higher Plant Leaves." Journal of Plant Physiology 160 (3): 271-282. doi:10.1078/ 0176-1617-00887.

Gitelson, A. A., Y. J. Kaufman, and M. N. Merzlyak. 1996. "Use of a Green Channel in Remote Sensing of Global Vegetation from EOS-MODIS." Remote Sensing of Environment 58 (3): 289298. doi:10.1016/S0034-4257(96)00072-7.

Gobron, N., B. Pinty, M. M. Verstraete, and J. L. Widlowski. 2000. "Advanced Vegetation Indices Optimized for Up-Coming Sensors: Design, Performance, and Applications." IEEE Transactions on, Geoscience and Remote Sensing 38: 2489-2505. doi:10.1109/36.885197.

Guyot, G., F. Baret, and S. Jacquemoud. 1992. "Imaging Spectroscopy for Vegetation Indices." In Imaging Spectroscopy: Fundamentals and Prospective Applications, edited by F. Toselli, and J. Bodechtel, 145-165. Dordrecht: Kluwer.

Huete, A., C. Justice, and W. van Leeuwen. 1999. "MODIS Vegetation Index (MOD 13) Algorithm Theoretical Basis Document Version 3." NASA. http://modis.gsfc.nasa.gov/data/atbd/atbd_mod13.pdf

Huete, A. R. 1988. “A Soil-Adjusted Vegetation Index (SAVI)." Remote Sensing of Environment 25 (3): 295-309. doi:10.1016/0034-4257(88)90106-X.

Hunt, E. R. Jr, and B. N. Rock. 1989. "Detection of Changes in Leaf Water Content Using Near- and Middle-Infrared Reflectances." Remote Sensing of Environment 30 (1): 43-54. doi:10.1016/ 0034-4257(89)90046-1.

Jensen, J. R. 2014. Remote Sensing of the Environment: Pearson New International Edition: An Earth Resource Perspective. 2nd ed. New York: Pearson.

Karnieli, A., Y. J. Kaufman, L. Remer, and A. Wald. 2001. "AFRI - Aerosol Free Vegetation Index." Remote Sensing of Environment 77: 10-21. doi:10.1016/S0034-4257(01)00190-0.

Kaufman, Y. J., and D. Tanre. 1992. "Atmospherically Resistant Vegetation Index (ARVI) for EOSMODIS.” IEEE Transactions on Geoscience and Remote Sensing 30 (2): 261-270. doi:10.1109/ 36.134076.

Key, C. H., N. Benson, D. Ohlen, S. Howard, R. McKinley, and Z. Zhu. 2002. "The Normalized Burn Ratio and Relationships to Burn Severity: Ecology, Remote Sensing and Implementation." In Proceedings of the Ninth Forest Service Remote Sensing Applications Conference, San Diego, CA, April 8-12, Bethesda, MD: American Society for Photogrammetry and Remote Sensing.

Khanna, S., M. J. Santos, S. L. Ustin, A. Koltunov, R. F. Kokaly, and D. A. Roberts. 2013. "Detection of Salt Marsh Vegetation Stress and Recovery after the Deepwater Horizon Oil Spill in Barataria Bay, Gulf of Mexico Using AVIRIS Data." PLoS ONE 8 (11): e78989. 
Li, L., S. L. Ustin, and M. Lay. 2005. "Application of AVIRIS Data in Detection of Oil-Induced Vegetation Stress and Cover Change at Jornada, New Mexico." Remote Sensing of Environment 94 (1): 1-16. doi:10.1016/j.rse.2004.08.010.

Liu, H. Q., and A. Huete. 1995. "A Feedback Based Modification of the NDVI to Minimize Canopy Background and Atmospheric Noise." IEEE Transactions on Geoscience and Remote Sensing 33 (2): 457-465. doi:10.1109/36.377946.

Liu, W. X., Y. M. Luo, Y. Teng, Z. G. Li, and L. H. Wu. 2007. "A Survey of Petroleum Contamination in Several Chinese Oilfield Soils." Soils 39: 247-251.

Louhaichi, M., M. M. Borman, and D. E. Johnson. 2001. "Spatially Located Platform and Aerial Photography for Documentation of Grazing Impacts on Wheat." Geocarto International 16 (1): 65-70. doi:10.1080/10106040108542184.

Main, R., M. A. Cho, R. Mathieu, M. M. O'Kennedy, A. Ramoelo, and S. Koch. 2011. "An Investigation into Robust Spectral Indices for Leaf Chlorophyll Estimation." ISPRS Journal of Photogrammetry and Remote Sensing 66 (6): 751-761. doi:10.1016/j.isprsjprs.2011.08.001.

Metternicht, G. 2003. "Vegetation Indices Derived from High-Resolution Airborne Videography for Precision Crop Management." International Journal of Remote Sensing 24 (14): 2855-2877. doi:10.1080/01431160210163074.

Motohk, T., K. N. Nasahara, H. Oguma, and S. Tsuchida. 2010. "Applicability of Green-Red Vegetation Index for Remote Sensing of Vegetation Phenology." Remote Sensing 2 (10): 2369-2387.

Myneni, R. B., S. Hoffman, Y. Knyazikhin, J. L. Privette, J. Glassy, Y. Tian, Y. Wang, et al. 2002. "Global Products of Vegetation Leaf Area and Fraction Absorbed PAR from Year One of MODIS Data." Remote Sensing of Environment 83: 214-231. doi:10.1016/S0034-4257(02) 00074-3.

Noomen, M. F., H. M. A. Van Der Werff, and F. D. Van Der Meer. 2012. "Spectral and Spatial Indicators of Botanical Changes Caused by Long-Term Hydrocarbon Seepage." Ecological Informatics 8: 55-64. doi:10.1016/j.ecoinf.2012.01.001.

Oliveira, W. J. D., A. P. Crosta, and J. L. M. Goncalves. 1997. "Spectral Characteristics of Soils and Vegetation Affected by Hydrocarbon Gas: A Greenhouse Simulation of the Remanso Do Fogo Seepage." In Twelfth International Conference and Workshops on Applied Geologic Remote Sensing, Denver, CO, November 17-19. Ann Arbor, MI: Erim International.

Peñuelas, J., I. Filella, C. Biel, L. Serrano, and R. Savé. 1993. "The Reflectance at the 950-970 Nm Region as an Indicator of Plant Water Status." International Journal of Remote Sensing 14 (10): 1887-1905. doi:10.1080/01431169308954010.

Qi, J., A. Chehbouni, A. R. Huete, Y. H. Kerr, and S. Sorooshian. 1994. "A Modified Soil Adjusted Vegetation Index." Remote Sensing of Environment 48 (2): 119-126. doi:10.1016/ 0034-4257(94)90134-1.

Raghavan, V. 2000. Developmental Biology of Flowering Plants. New York: Springer.

Rondeaux, G., M. Steven, and F. Baret. 1996. "Optimization of Soil-Adjusted Vegetation Indices." Remote Sensing of Environment 55 (2): 95-107. doi:10.1016/0034-4257(95)00186-7.

Rouse, J. W.Jr., R. H. Haas, J. A. Schell, and D. W. Deering. 1973. "Monitoring the Vernal Advancement and Retrogradation (Green Wave Effect) of Natural Vegetation." Prog. Rep. RSC 1978-1, 93.

Saleska, S. R., K. Didan, A. R. Huete, and H. R. Da Rocha. 2007. "Amazon Forests Green-Up during 2005 Drought.” Science 318 (5850): 612. doi:10.1126/science.1146663.

Simonich, S. L., and R. A. Hites. 1995. "Organic Pollutant Accumulation in Vegetation." Environmental Science \& Technology 29 (12): 2905-2914. doi:10.1021/es00012a004.

Sripada, R. P., R. W. Heinigerb, J. G. Whitec, and A. D. Meijer. 2006. "Aerial Color Infrared Photography for Determining Early In-Season Nitrogen Requirements in Corn." Agronomy Journal 98 (4): 968-977. doi:10.2134/agronj2005.0200.

Teillet, P. M., K. Staenz, and D. Williams. 1997. "Effects of Spectral, Spatial, and Radiometric Characteristics on Remote Sensing Vegetation Indices of Forested Regions." Remote Sensing of Environment 61 (1): 139-149. doi:10.1016/S0034-4257(96)00248-9.

Tucker, C. J. 1979. "Red and Photographic Infrared Linear Combinations for Monitoring Vegetation." Remote Sensing of Environment 8 (2): 127-150. doi:10.1016/0034-4257(79) 90013-0. 
UNEP, United Nations Environment Programme. 2011. "Environmental Assessment of Ogoniland." UNEP. hwww.unep.org/disastersandconflicts/CountryOperations/Nigeria/ EnvironmentalAssessmentofOgonilandreport

Van Der Meer, F., P. Van Dijk, S. Kroonenberg, Y. Hong, and H. Lang. 2000. "Hyperspectral Hydrocarbon Microseepage Detection and Monitoring: Potentials and Limitations." In Proceedings of the Second EARsel Workshop on Imaging Spectroscopy. Enschede, Muster: EARSeL. http://www.earsel.org/workshops/imaging-spectroscopy-2000/index.html

Van Der Meer, F., P. Van Dijk, H. Van Der Werff, and H. Yang. 2002. "Remote Sensing and Petroleum Seepage: A Review and Case Study." Terra Nova 14: 1-17. doi:10.1046/ j.1365-3121.2002.00390.x.

Van Der Meijde, M., H. M. A. Van Der Werff, P. F. Jansma, F. D. Van Der Meer, and G. J. Groothuis. 2009. "A Spectral-Geophysical Approach for Detecting Pipeline Leakage." International Journal of Applied Earth Observation and Geoinformation 11 (1): 77-82. doi:10.1016/j.jag.2008.08.002.

Van Der Werff, H., M. Van Der Meijde, F. Jansma, F. Van Der Meer, and G. Groothuis. 2008. "A Spatial-Spectral Approach for Visualization of Vegetation Stress Resulting from Pipeline Leakage." Sensors 8 (6): 3733-3743. doi:10.3390/s8063733.

Van Der Werff, H. M. A., M. F. Noomen, M. Van Der Meijde, and F. D. Van Der Meer. 2007. "Remote Sensing of Onshore Hydrocarbon Seepage: Problems and Solutions." Geological Society, London, Special Publications 283: 125-133. doi:10.1144/SP283.11.

Wang, F., J. Huang, Y. Tang, and X. Wang. 2007. "New Vegetation Index and Its Application in Estimating Leaf Area Index of Rice." Rice Science 14 (3): 195-203. doi:10.1016/ S1672-6308(07)60027-4.

Wu, C., Z. Niu, Q. Tang, and W. Huang. 2008. "Estimating Chlorophyll Content from Hyperspectral Vegetation Indices: Modeling and Validation." Agricultural and Forest Meteorology 148 (8-9): 1230-1241. doi:10.1016/j.agrformet.2008.03.005.

Yoder, B. J., and R. H. Waring. 1994. "The Normalized Difference Vegetation Index of Small Douglas-Fir Canopies with Varying Chlorophyll Concentrations." Remote Sensing of Environment 49 (1): 81-91. doi:10.1016/0034-4257(94)90061-2.

Zarco-Tejada, P. J., A. Berjón, R. López-Lozano, J. R. Miller, P. Martín, V. Cachorro, M. R. González, and A. De Frutos. 2005. "Assessing Vineyard Condition with Hyperspectral Indices: Leaf and Canopy Reflectance Simulation in a Row-Structured Discontinuous Canopy.” Remote Sensing of Environment 99 (3): 271-287. doi:10.1016/j.rse.2005.09.002. 